\title{
SUPERAÇÃO DOS MODELOS HEGEMÔNICOS NA FORMAÇÃO DE PROFESSORES DO CAMPO EM CIÊNCIAS DA NATUREZA
}

\author{
OVERCOMING HEGEMONIC MODELS IN THE TRAINING OF FIELD EDUCATION' \\ TEACHERS IN NATURE SCIENCES
}

\section{SUPERAR LOS MODELOS HEGEMÓNICOS EN LA FORMACIÓN DE PROFESORES DE CAMPO EN CIENCIAS DE LA NATURALEZA}

\author{
Geize Kelle Nunes Ribeiro \\ ORCID iD: https://orcid.org/0000-0003-4053-7788 \\ Mestra em Educação - UFCat-GEPEEC - Brasil \\ Wender Faleiro \\ ORCID iD: https://orcid.org/0000-0001-6419-296X \\ Pós Doutor - PUC-GO-GEPEEC - UFCat - Brasil
}

\begin{abstract}
Resumo: Objetivamos realizar uma discussão sobre a Formação crítica/conscientizadora e a superação dos modelos hegemônicos na formação de professores do Campo. Para atingi-la utilizamos da análise documental dos Projetos Político-Pedagógicos dos cursos de Licenciatura em Educação do Campo com habilitação em Ciências da Natureza no Brasil. Os PPPs analisados concebem a formação crítica/conscientizadora/reflexiva capaz de transformar a realidade local, regional e nacional a partir da compreensão do contexto social, político, econômico, cultural e educacional. Os cinco PPPs analisados demonstram a interesse em superar esse protótipo de formação docente, trazendo como de suma importância a especificidade da formação docente para a atuação do professor no Campo. Em face da superação da fragmentação do conhecimento, teoricamente, todos os cursos atendem a esse princípio, porque oferecem a Licenciatura em Educação do Campo por área do conhecimento.
\end{abstract}

Palavras chave: Formação de professores; Formação por área; Projetos Político-Pedagógicos

\begin{abstract}
We aimed at the discussion Critical / awareness-raising training and overcoming hegemonic models in the training of rural teachers. to achieve it we used the documentary analysis of the Political-Pedagogical Projects of the Degree in Rural Education courses with qualification in Natural Sciences in Brazil. The analyzed PPPs conceive the critical / awareness / reflexive formation capable of transforming the local, regional and national reality from the understanding of the social, political, economic, cultural and educational context. The five PPPs analyzed show an interest in overcoming this teacher training prototype, bringing the specificity of teacher training to the role of the teacher in the field as extremely important. In view of overcoming the fragmentation of knowledge, theoretically, all courses meet this principle, because they offer the Degree in Rural Education by area of knowledge.
\end{abstract}


Keywords: Teacher training; Training by area; Political-Pedagogical Projects.

Resumen: Apuntamos a la discusión Formación crítica / sensibilizadora y superación de modelos hegemónicos en la formación de docentes rurales, para lograrlo utilizamos el análisis documental de los Proyectos Político-Pedagógicos de la Licenciatura en Educación Rural con titulación en Ciencias Naturales en Brasil. . Los PPP analizados conciben la formación crítica / sensibilización / reflexiva capaz de transformar la realidad local, regional y nacional desde la comprensión del contexto social, político, económico, cultural y educativo. Las cinco APP analizadas muestran un interés por superar este prototipo de formación docente, aportando como especial importancia la especificidad de la formación docente para el desempeño del docente en el campo. Con vistas a superar la fragmentación del conocimiento, teóricamente todos los cursos cumplen con este principio, porque ofrecen el Grado en Educación Rural por áreas de conocimiento.

Palabrasclave: Formación de profesores; Entrenamiento por área; Proyectos político-pedagógicos

\section{Introdução}

Prevalece a desigualdade em nossa sociedade na qual, poder, saber e palavra não são conduzidos com equidade, mas distribuídos hierarquicamente de diferentes modos, repartidos de acordo com a divisão social do trabalho. Dessa forma, são poucos os que possuem o direito de dizer a palavra, de garantir a "verdade" e apresentar um conhecimento "legítimo". Na verdade, existimos em um mundo social governado pelos interesses de senhores do poder que, através de um Estado de democracia restrita, decidem e definem normas, regras e direitos da vida coletiva, as quais devem ser obedecidas pelos demais (BRANDÃO, 2012).

Nesse contexto é notável o posicionamento da escola diante desse processo de dominação/subordinação social. A escola tem sido instrumento de propagação das relações em sociedade, tem se tornado cada vez mais seletiva, segregadora e marginalizadora. Isso acontece na medida em que a escola desenvolve a função de adaptar e ajustar os educandos à sociedade, a partir de dons, talentos e aptidões individuais; de "compensar" os déficits socioculturais, porque "alguns" alunos são carentes e privados de cultura, "sem cultura"; de tratar a diferença como deficiência. Além disso, o problema é que o fracasso escolar ${ }^{1}$ é justamente característica dos

\footnotetext{
1 Magda Soares (2017, p. 133,134) apresenta que "por fracasso escolar deve-se entender tanto fracasso na escola quanto fracasso da escola. A expressão fracasso na escola põe o foco nos alunos, em seu insucesso no seu processo de escolarização [...]. Grande parte desse fracasso na
} 
alunos pertencentes às camadas desfavorecidas ${ }^{2}$ e esse efeito acentua e legitima as desigualdades sociais (SOARES, 2017).

Podemos ver a luta das camadas populares em nossa sociedade por reconhecimento de suas identidades, por direitos, respeito e pela chance de se viver mais dignamente. Diante disso surge a Educação do Campo, como resultado da pressão e das demandas dos trabalhadores e trabalhadoras do Campo, dos Movimentos Sindicais e Sociais. Assim, o presente estudo visa a discussão da Formação crítica/conscientizadora e superação dos modelos hegemônicos na formação de professores do Campo, ressaltando a importância do Curso de Licenciatura em Educação do Campo (LEdoC) como instrumento de luta por uma Educação Básica que valorize a identidade do povo campesino e atenda suas necessidades enquanto sujeitos de direitos.

Assim, contemplarmos os aspectos filosóficos e alguns pedagógicos que embasam os Projetos Político Pedagógicos dos Cursos nos possibilita perceber a ação educativa e pedagógica desenvolvida pela Universidade a partir da compreensão de suas finalidades e objetivos. Veiga (2013, p. 23) menciona que "as finalidades da escola referem-se aos efeitos intencionalmente pretendidos e almejados", o que concorda com a ideia de Freire (2001, p. 21) ao afirmar que "[...] não pode existir uma prática educativa neutra, descomprometida, apolítica”. Dessa forma, decidimos articular as contribuições de Arroyo (2012), que aborda os principais aspectos para entendermos a formação de educadores/professores do Campo, com as de Farias e Faleiro (2019), que discutem a formação de professores do Campo entrelaçada aos princípios do Movimento da Educação do Campo, conforme apresentado no Quadro 1. Vale ressaltar que as categorias levantadas no trabalho de Arroyo (2012a) não estão explícitas no texto, foram elaboradas de acordo com o estudo dos apontamentos do autor. Já em Farias e Faleiro (2019), as categorias estão explícitas.

escola é consequência do fracasso da escola brasileira, resultante de políticas públicas ausentes ou ineficientes".

2 Usamos a definição de Magda Soares (2017), que emprega o termo camadas desfavorecidas para designar os indivíduos ou grupo de indivíduos que constituem uma camada qualificada "pelo critério de privação de bens, de benefícios, de adequadas condições econômicas, sociais, culturais". O termo camadas populares é empregado como sinônimo de camadas desfavorecidas. 
Os aspectos discutidos por Arroyo (2012) dialogam intrinsecamente com o princípio proposto por Farias e Faleiro (2019, 186-187), que argumentam:

A superação de modelos hegemônicos de formação é um dos pressupostos da LEdoC, tendo em vista seu compromisso político e social para a formação de educadores críticos. Assim, exige-se a superação de uma pedagogia hegemônica ou do capital que tem como papel central a formação de professores para a manutenção das relações de opressão capitalistas (NEVES, 2013; NEVES, 2005; MARTINS; NEVES, 2010), colocando em prática uma pedagogia do oprimido, decolonial e dos Movimentos Sociais, ou seja, uma formação de educadores capazes de adquirirem uma leitura crítica/problematizadora das relações de opressão e que surja junto e a partir dos Movimentos Sociais do Campo, focalizando as transformações das contradições sociais (CALDART, 2008; FREIRE, 1987; II CONFERÊNCIA, 2004; ARROYO, 1999).

Logo, a discussão dessa categoria perpassa os aspectos apresentados no Quadro 1 - Aspectos da formação de educadores do Campo propostos por Arroyo: 1) Formação de professores com capacidade crítica/reflexiva para transformar a realidade; 2) Superação da formação genérica de docente; 3) Superação da fragmentação do conhecimento; 4) Superação do pensamento abissal.

Quadro 1 - Articulação entre as noções de formação de professores do Campo segundo Arroyo (2012) e Farias e Faleiro (2019).

\begin{tabular}{|l|l|}
\hline \multicolumn{1}{|c|}{$\begin{array}{c}\text { Aspectos da formação de educadores do Campo } \\
\text { propostos por Arroyo (2012) }\end{array}$} & $\begin{array}{l}\text { Categorias de análise para a } \\
\text { formação de professores do } \\
\text { Campo (Farias; Faleiro, 2019) }\end{array}$ \\
\hline $\begin{array}{l}\text { Superar a formação de protótipo único, genérico de } \\
\text { docente-educador para a Educação Básica }\end{array}$ & $\begin{array}{l}\text { Formação crítica/conscientizadora } \\
\text { e superação dos modelos } \\
\text { hegemônicos }\end{array}$ \\
\cline { 1 - 1 } $\begin{array}{l}\text { Formar professores com capacidade crítica, reflexiva } \\
\text { para transformar a realidade }\end{array}$ & $\begin{array}{l}\text { Protagonismo dos Movimentos } \\
\text { Sociais }\end{array}$ \\
\cline { 1 - 2 } Superar a fragmentação do conhecimento & \\
\cline { 1 - 2 } $\begin{array}{l}\text { Repensar e redefinir a relação entre o Estado, as } \\
\text { instituições e os Movimentos Sociais }\end{array}$ & Vinculação com a cultura, trabalho \\
\cline { 1 - 2 } $\begin{array}{l}\text { Superar visões inferiorizantes de outras formas de } \\
\text { pensar, de outras culturas e seus coletivos e avançar } \\
\text { para posturas de reconhecimento e diálogo entre } \\
\text { modos de pensar }\end{array}$ & \\
\cline { 1 - 2 } $\begin{array}{l}\text { Reconhecer/incorporar a riqueza de saberes do } \\
\text { trabalho, da terra, das experiências e das ações } \\
\text { coletivas e sociais dos povos do Campo }\end{array}$ \\
\hline
\end{tabular}




\begin{tabular}{|l|l|}
\hline $\begin{array}{l}\text { Incorporar a história de produção das desigualdades } \\
\text { e das relações políticas de dominação/subordinação } \\
\text { da agricultura, dos povos do Campo e seus } \\
\text { trabalhadores à lógica do capital }\end{array}$ & $\begin{array}{l}\text { Formação para a construção de } \\
\text { um projeto de Campo e sociedade }\end{array}$ \\
\hline $\begin{array}{l}\text { Incorporar uma formação plural para funções plurais } \\
\text { (educativa, diretiva e organizativa) }\end{array}$ & \\
\hline- & Formação por Alternância \\
\hline
\end{tabular}

Fonte: Elaborado para o presente estudo (2020).

Reconhecemos que as categorias propostas pelos autores abordam a formação de professores do Campo com mais complexidade e abrangência, o que pode ser esperado, porque Arroyo (2012) não apresenta categorias especificamente, mas sim a concepção, definição de formação de educadores do Campo, a discussão do que se espera para a formação desse profissional. No entanto, sempre que necessário recorremos ao autor para fundamentarmos a nossa discussão. Ressaltamos que o autor ainda destaca em sua abordagem que "A concepção e a política de formação de professores do Campo vão se construindo na conformação da Educação do Campo" (ARROYO, 2012, p. 359), o que também valida a nossa escolha.

Com essas reminiscências, esse estudo objetiva a discussão Formação crítica/conscientizadora e superação dos modelos hegemônicos na formação de professores do Campo em Ciências da Natureza no Brasil.

\section{Metodologia}

Buscando assegurar a construção dos dados para atingir o objetivo principal do estudo utilizamos as técnicas da análise documental dos Projetos Político-Pedagógicos (PPPs) dos cursos de Licenciatura em Educação do Campo (LEdoC) com habilitação em Ciências da Natureza no Brasil. A escolha desses documentos deve-se ao fato de entendermos os PPPs como essenciais para a institucionalização e consolidação dos cursos em análise. E, ainda, concordamos com Farias e Faleiro (2019, p. 129) ao afirmarem que:

O PPP surge enquanto alternativa para se vislumbrar possibilidades, formas e estratégias para resolver, debater e materializar questões que se caracterizam como problemáticas no processo educativo. Vai além de uma lista de planos e atividades, é um processo vivenciado nos diversos momentos da instituição, na busca por uma direção. É 
uma ação com intencionalidade, de um processo coletivo na co-responsabilização dos diversos sujeitos que compõem a dinâmica educativa, levando em consideração tensões locais, nacionais e globais (VEIGA, 2007). Fagundes (2009) discorre sobre o PPP enquanto instrumento de mediação entre as produções sociais e pedagógicas.

Sobre o universo da nossa pesquisa, dos quarenta e dois cursos de Licenciaturas em Educação do Campo que oferecem habilitação em quatro áreas de conhecimento: 1) Artes; 2) Literatura e Linguagens; 3) Ciências da Natureza e Matemática; 4) Ciências Agrárias (MOLINA; SÁ, 2012), desses 18 oferecem habilitação em Ciências da Natureza dos quais analisamos cinco PPPs, sendo um de cada IES referente à uma região geográfica do país. Optamos por trabalhar apenas com as Instituições de Ensino Superior que ofertam os cursos com habilitação em Ciências da Natureza por ser uma recomendação, preferência, do Edital n. 02/2012 (Chamada Pública para seleção de Instituições Federais de Educação Superior - IFES e de Institutos Federais de Educação, Ciência e Tecnologia - IFET, para criação de cursos de Licenciatura em Educação do Campo, na modalidade presencial), a fim de atender a demanda de docentes habilitados nesta área nas escolas rurais. Os critérios de seleção das cinco IES, no ano de 2018, foram os seguintes:

Serem cursos ofertados em Universidades, considerando apenas um modelo de trabalho institucional (13 cursos).

$\checkmark$ Possuírem o PPP disponível no site oficial das Universidades (9 cursos).

Como a amostragem ainda era grande foram adotados alguns parâmetros específicos para a escolha de uma IES por região geográfica do Brasil: Para as regiões Norte, Nordeste e Sudeste foi levado em consideração a página do curso que apresentava melhor estruturação e informações disponíveis. Para a região Centro-oeste, os pesquisadores não possuem nenhum vínculo com a instituição. $E$, para a região Sul, escolhemos a instituição que está inserida em um assentamento, o que não é a realidade das demais LEdoCs. O Quadro 2 apresenta as LEdoCs 
selecionadas para este estudo e indica como os PPPs foram identificados: letra "P" seguida de um número.

Quadro 2 - Identificação das cinco Universidades selecionadas para análise do PPP de suas licenciaturas em Educação do Campo com habilitação em Ciências da Natureza.

\begin{tabular}{|c|c|c|c|}
\hline $\begin{array}{c}\text { Região } \\
\text { geográfica }\end{array}$ & Universidade & Estado & Identificação \\
\hline Norte & Universidade Federal de Rondônia \\
(UNIR) & Rondônia & P-1 \\
\hline Nordeste & $\begin{array}{c}\text { Universidade Federal Rural do } \\
\text { Semiárido (UFERSA) }\end{array}$ & $\begin{array}{c}\text { Rio Grande do } \\
\text { Norte }\end{array}$ & $\mathrm{P}-2$ \\
\hline Centro-Oeste & $\begin{array}{c}\text { Universidade Federal da Grande } \\
\text { Dourados (UFGD) }\end{array}$ & $\begin{array}{c}\text { Mato Grosso do } \\
\text { Sul }\end{array}$ & $\mathrm{P}-3$ \\
\hline Sudeste & $\begin{array}{c}\text { Universidade Federal do Triângulo } \\
\text { Mineiro (UFTM) }\end{array}$ & Minas Gerais & $\mathrm{P}-4$ \\
\hline Sul & $\begin{array}{c}\text { Universidade Federal da Fronteira do } \\
\text { Sul (UFFS) }\end{array}$ & Santa Catarina & $\mathrm{P}-5$ \\
\hline
\end{tabular}

Fonte: Elaborado para o presente estudo (2020).

Com a definição das cinco IES e com a coleta do PPP de suas licenciaturas em Educação do Campo e habilitação em Ciências da Natureza, fizemos uso da Análise de Conteúdo para tratarmos os nossos dados.

\section{Resultados e Discussão}

$$
\text { Quando se fala em capacidade crítica/reflexiva é impossível }
$$

não associarmos a dois conceitos muito importantes presentes nas obras de Paulo Freire (2017; 2018), e que são discutidos com afinco por Kronbauer (2017), criticidade e ação-reflexão. Freire (2018, p. 32, 33) assegura que "ensinar exige criticidade":

Não há para mim, na diferença e na "distância" entre ingenuidade e a criticidade, entre o saber de pura experiência feito e o que resulta dos procedimentos metodicamente rigorosos, uma ruptura, mas uma superação. A superação e não a ruptura se dá na medida em que a curiosidade ingênua, sem deixar de ser curiosidade, pelo contrário, continuando a ser curiosidade, se criticiza. Ao criticizar-se, tornando-se então, permito-me repetir, curiosidade epistemológica, metodicamente "rigorizando-se" na aproximação ao objeto, conota seus achados de maior exatidão. 
Nesse sentido, o autor relaciona a curiosidade ingênua ao saber do senso comum, que se torna curiosidade epistemológica ao se criticizar, "aproximando-se de forma cada vez mais metodicamente rigorosa do objeto cognoscível". Kronbauer (2017, p. 23, 24), nos ajuda a entender melhor a respeito dessa questão, ao discutir sobre o conceito de ação-reflexão na obra de Freire. Ele argumenta que é "o saber que realimenta criticamente o fazer, cujo resultado incide sobre o saber e, assim ambos se refazem continuamente". Em outras palavras, "o ato de conhecer envolve um movimento dialético que da ação à reflexão sobre ela e desta para uma nova ação". Ainda, o autor descreve que:

É a prática consciente de seres humanos, que implica reflexão, intencionalidade, temporalidade e transcendência, diferentemente dos meros contatos dos animais com o meio que os envolve. Os seres humanos podem refletir sobre suas limitações e podem projetar a ação para transformar a realidade que os condiciona. Por conta da dialética ação-reflexão afirmam-se sujeitos, seres de relação, no mundo, com o mundo, e com os outros, pela mediação do mundo-linguagem (KRONBAUER, 2017, p. 24).

Dessa forma, é possível compreender que a criticidade está correlacionada à ação-reflexão, considerando que o pensar crítico leva-nos a problematizar "as condições de existências humana no mundo, desafia para a luta e a busca de superação das condições de vida desumanizadoras" (MOREIRA, 2017, p. 97).

Ainda,

A criticidade, para Paulo Freire, é a capacidade do educando e do educador refletirem criticamente a realidade na qual estão inseridos, possibilitando a constatação, o conhecimento e a intervenção para transformá-la. Essa capacidade exige rigor metodológico, que combine o "saber da pura experiência com o "conhecimento organizado", mais sistematizado. O principal objetivo é fazer com que as pessoas e as classes oprimidas, que aceitam esse desafio, possam pensar certo e se constituírem como sujeitos históricos e sociais, que pensam, criticam, opinam, têm sonhos, se comunicam e dão sugestões (FREIRE, 1997 apud MOREIRA, 2017, p. 97).

Assim, todos os documentos analisados estão orientados para a formação crítico-reflexiva do/a professor/a para que haja transformação da realidade na qual ele/a está inserido/a. Concordamos com Moreira (2017, p. 98) ao mencionar que

a ação transformadora da realidade, enquanto um exercício da criticidade em direção à práxis política, constitui-se a partir de 
práticas educativas que despertam a curiosidade epistemológica dos educandos e contribuem para a construção de um novo projeto, de um novo sonho de sociedade e mundo a favor das pessoas e classes oprimidas.

Citando, por exemplo, P-1 (2014, p. 22, grifos nossos), no que diz respeito ao "Perfil do Egresso", tem-se que o/a egresso/a deverá desenvolver a "Leitura histórico crítica da realidade promovendo ações propositivas como forma de enfrentamento dos problemas a ela inerentes”. Já em P-2 (2013, p. 18, grifos nossos), "[...] incorporar práticas pedagógicas que promovam o desenvolvimento social". Nesse caso, acreditamos que o desenvolvimento social é uma consequência da transformação da realidade que os povos do Campo vivem. O P-3 (2017, p. 15, grifos nossos), aborda como um de seus objetivos gerais,

Formar licenciados/as em Ciências da Natureza e Ciências Humanas com uma sólida formação humanística, que sejam capazes de atuar como profissionais críticos/as da realidade multidimensional da sociedade brasileira, do processo educacional e nas organizações dos Movimentos Sociais [...].

Já o Tópico "Perfil profissional do Egresso" afirma que "assim, [os acadêmicos/cidadãos/as] poderão desempenhar sua profissão com responsabilidade, espírito crítico e com coerência teórico, científica e metodológica, na área de ensino como educadores político-sociais" (P-3, 2017, p. 16, grifo nosso). P-4 (2014, p. 87, grifos nossos) por sua vez, expõe que ao decorrer dos quatro anos da formação docente, o/a licenciando/a

vivenciará processos formativos pautados nas inovações tecnológicas, pedagógicas, culturais, políticas de base crítica permitindo-Ihe a construção de perfil pedagógico-científico capaz de [...] criar estratégias de produção de conhecimento apropriadas para interferir na realidade agrária local, regional e nacional em favor dos povos do Campo.

E em P-5 (2013, p. 38, grifos nossos), um dos objetivos específicos é explanado como:

Promover a formação de profissionais capacitados para atuar em Escolas do Campo de modo que utilizam os conhecimentos das Ciências da Natureza articulados com as demandas para produzir a vida no Campo, valendo-se do ensino, da pesquisa e da extensão para compreender e transformar o contexto social, político, econômico, cultural e educacional do seu meio. 
Além do mais, entende-se que o profissional atuará objetivando o desenvolvimento local, regional e nacional:

o docente egresso deste curso deverá inserir-se em seus respectivos contextos profissionais de forma: autônoma, solidária, crítica, reflexiva e comprometida com o desenvolvimento local, regional e nacional sustentáveis, objetivando a construção de uma sociedade justa e democrática (P-5, 2013, p. 39, grifos nossos).

Este documento ainda enfatiza que

o egresso deste curso precisa ser capaz de utilizar os conhecimentos das Ciências da Natureza construídos por meio do ensino, da pesquisa e da extensão, para compreender e transformar o contexto sociopolítico do seu meio, entendendo as relações que se estabelecem entre ciência, tecnologia e sociedade, agindo dentro [dos] pressupostos de um desenvolvimento sustentável nos diferentes espaços educativos da sociedade (P-5, 2013, p. 40, grifos nossos).

Logo, podemos perceber que os PPPs analisados concebem a formação crítica/conscientizadora/reflexiva capaz de transformar a realidade local, regional e nacional a partir da compreensão do contexto social, político, econômico, cultural e educacional. Nós cremos nisso! Todavia, sem a superação da formação genérica de professores não há mudança, não há como transformar a escola. Uma vez que é pela formação específica, contra-hegemônica, crítica/problematizadora, que conseguiremos construir, instruir, professores/educadores compromissados com a transformação política e social e com a formulação de práticas escolares e educativas capazes de cumprir os objetivos desse processo formativo e as intencionalidades da Educação do Campo.

\section{Superação da formação genérica de professores}

Entendemos que a atual formação de professores prevê uma formação genérica, à medida que acredita que todo professor está capacitado para desenvolver seu papel independentemente das subjetividades/heterogeneidades de seu alunado. Nesse sentido, Arroyo (2012, p. 359) afirma que

Se a condição docente é pensada como única e as diretrizes que regulamentam a sua formação também são únicas, só resta aplicá-las com as "permitidas" adaptações em tempos, cargas 
horárias, nos tipos presencial ou em Alternância ou em comunidade etc. [...] Ao serem incorporados como cursos das universidades poderão ser pressionados a perder seu caráter específico, sendo reduzidos a secundárias adaptações.

Isto é justamente o que as Diretrizes Curriculares Nacionais Gerais para a Educação Básica (BRASIL, 2013, p. 45, grifos nossos) orientam sobre a oferta da Educação Básica do Campo:

A educação para a população rural está prevista no artigo 28 da LDB, em que ficam definidas, para o atendimento à população rural, adaptações necessárias às peculiaridades da vida rural e de cada região, definindo orientações para três aspectos essenciais à organização da ação pedagógica: (I) - conteúdos curriculares e metodologias apropriadas às reais necessidades e interesses dos estudantes da zona rural; (II) - organização escolar própria, incluindo adequação do calendário escolar às fases do ciclo agrícola e às condições climáticas; (III) - adequação à natureza do trabalho na zona rural.

Dessa forma, sem a superação desse modelo de formação reproduzimos o protótipo que: privilegia a visão urbanocêntrica; vê a especificidade do Campo como algo provisório, porque acredita que em breve o processo de urbanização homogeneizará todo o território nacional; prioriza o transporte de professores da cidade para as escolas do Campo, os quais não possuem vínculo com a cultura nem com os saberes campesinos; o inverso também é verdadeiro, prioriza o transporte dos estudantes do Campo para a cidade. Ademais, a luta em defesa de uma educação aos povos do Campo, é uma luta por uma educação específica, emancipadora e, não adaptada, adequada, enfim remendada e que se perde e se inferioriza com o tempo.

Arroyo (2012, p. 359,340) ainda aborda que

[...] os movimentos, ao defenderem a especificidade da formação, não defendem uma função genérica nem um Currículo único com as devidas adaptações. E nem retornam à proposta do ruralismo pedagógico, mas superam a visão da escola rural e do professor rural ao politizarem a Educação do Campo em um outro projeto de Campo.

Peres e Santana (2016, p. 135, grifo nosso) complementam essa ideia: "a formação inicial deve estar atrelada à realidade na qual o professor atuará, proporcionando uma reflexão crítica sobre a importância do docente na sociedade 
atual; não é possível querer uma educação de qualidade sem investir numa boa formação inicial e continuada".

Diante do exposto, os cinco PPPs analisados demonstram interesse em superar esse protótipo de formação docente, trazendo como de suma importância a especificidade da formação docente para a atuação do professor no Campo. Apenas o documento P-5 aborda esse princípio de modo contraditório. A seguir é apresentado o que cada PPP traz sobre o assunto, sendo que os recortes grifados referem-se à afirmação que nos leva a concluir tal assertiva.

O P-1 (2014, p. 13, grifos nossos), por exemplo, traz como objetivo geral:

Contribuir para a efetivação da inclusão social ao formar professores para os anos finais (segundo segmento) do Ensino Fundamental e Ensino Médio, no caráter de Licenciatura Plena em Educação do Campo, em consonância com a realidade socioeconômica e cultural específica das populações do campo, nas habilitações: Ciências da Natureza e Ciências Humanas e Sociais.

E ainda, P-1 (2014, p. 22, grifos nossos) no Tópico "Perfil do Egresso" traz a seguinte consideração: "Capacidade teórico-metodológica para implementação de estratégias pedagógicas pertinentes à realidade da Educação do Campo".

Em P-2 (2013, p. 18, grifos nossos), o objetivo geral, por sua vez, está descrito como: "Os/as educadores/as do campo formados pelas UFERSA estarão preparados para compreender a realidade social e cultural específica das populações que vivem no e do campo e incorporar práticas pedagógicas que promovam o desenvolvimento social". Ainda, no "Perfil do profissional" aborda que o graduando/a desse Curso deverá apresentar competências e habilidades relacionadas à: "Capacidade teórico-metodológica para a implementação de estratégias pedagógicas pertinentes à realidade da Educação do Campo" (P-2, 2013, p. 25, grifos nossos) e "Compreensão básica sobre os processos formadores dos sujeitos do campo" (P-2, 2013, p. 26, grifos nossos).

O P-3 (2017, p. 15, grifos nossos) tem dois objetivos gerais do curso, porém o que se refere a essa categoria propõe: "Fortalecer a educação e a possibilidade de ação qualificada no campo de Mato Grosso do Sul, com conhecimentos teórico-metodológicos voltados às especificidades, às necessidades e ao desenvolvimento sustentável do campo para a conquista de melhorias na qualidade de vida". E no "Perfil profissional do egresso" afirma que: "O curso tem 
como objetivo fundamental oferecer uma boa formação ao acadêmico/cidadão/a, construindo um perfil que corresponda às necessidades concretas do campo com suas especificidades e diversidade socioculturais" (P-3, 2017, p. 16, grifos nossos)

O P-4 (2014, p. 85, grifos nossos e sublinhados do documento) traz que o curso de Licenciatura em Educação do Campo objetiva:

Contribuir para a formação de professores e educadores em escolas do Campo (especialmente os que não possuem formação de nível superior) para atuar nos anos finais do Ensino Fundamental e Ensino Médio, como licenciados em Educação do Campo, nas habilitações das Ciências da Natureza ou da Matemática, tendo em vista a realidade socioeconômica e cultural específica das populações que trabalham e vivem no e do Campo.

No "Perfil profissional do egresso da Licenciatura em Educação do Campo da UFTM" indica que

Os egressos serão capazes de compreender a especificidades e a diversidade da população do Campo em seus aspectos social, cultural, econômico, de gênero e classe, assim como contribuir com essa população no processo de sistematização, articulação e potencialização dos seus saberes, a partir do diálogo com os saberes acadêmicos (P-4, 2014, p. 86-87, grifos nossos).

Por fim, P-5 (2013, p. 38, grifos nossos) não aborda claramente no objetivo geral ou nos objetivos específicos sobre o egresso compreender a especificidade campesina, mas traz que: "Desenvolver o processo de formação inicial do educador do Campo com ênfase em Ciências da Natureza, de modo que esteja capacitado para engajar-se aos desafios que se enlaçam à educação e à vida do e no Campo [...]". Entretanto, no Tópico "Perfil do Egresso", o documento afirma que "o egresso do curso Interdisciplinar em Educação do Campo - Licenciatura, com foco em Ciências da Natureza, deverá ter uma sólida formação acadêmica generalista, humanística e específica” (P-5, 2013, p. 39, grifos nossos).

Tendo como foco as duas palavras destacadas, entende-se que ambas se contradizem. Primeiramente, porque, conforme o Dicionário Priberam da Língua Portuguesa, o conceito de generalista é: 
1. Que tem caráter geral, não sendo especializado numa área específica (ex.: televisão generalista). 2. Que ou quem não tem uma especialização dentro da sua atividade regular (ex.: advogado generalista; valorizo os generalistas porque são multitarefas). 3. [Medicina] Diz-se de ou médico que exerce clínica geral (disponível em: <https://dicionario.priberam.org/generalista>, acesso em 04/04/2019, grifo nosso).

Dessa forma, tomando da definição apresentada, o item dois reduz a formação acadêmica generalista a uma formação sem especificidade para a atuação docente, o que foge ao eixo discutido neste estudo. Mas, o documento ainda defende uma formação acadêmica específica, o que impossibilita determinar se o curso realmente busca a superação do modelo de formação genérica de professores.

Outro aspecto a ser discutido aqui é a formação por área, e não por disciplinas, como possibilidade para a superação de modelos hegemônicos, uma vez que esta se propõe como estratégia para a superação da fragmentação do conhecimento.

A formação por áreas de conhecimento visa superar a fragmentação tradicional que dá centralidade à forma disciplinar e mudar o modo de produção do conhecimento na universidade e na escola do Campo, tendo em vista a compreensão da totalidade e da complexidade dos processos encontrados na realidade.

É necessário destacar o que Veiga (2004, p. 37) afirma sobre a base filosófica dessa fragmentação tradicional: "Dois aspectos dessa base filosófica merecem ser ressaltados: a separação entre o conhecimento científico e conhecimento proveniente do senso comum, e a separação entre a natureza e a pessoa humana. Nessa perspectiva, conhecer significa quantificar, dividir e classificar". Posteriormente, a autora complementa especificando alguns aspectos da formação e do Projeto Político-Pedagógico que podem contribuir com essa fragmentação. Em suma:

a) Concepção conservadora de ciência fundada nos princípios da racionalidade técnica, na separação entre teoria e prática, sujeito e objeto, ciência e sociedade, formação inicial, exercício profissional e formação continuada [...]; b) Estrutura curricular com pouca articulação conceitual entre as disciplinas [...]; c) A ausência de articulação na sequência e no alcance dessa sequência produz nos futuros 
professores um conhecimento atomizado, enfraquecido e muito pobre do ponto de vista relacional; d) O Currículo fragmentado [...], disciplinar, rígido e sem diálogo entre os diferentes saberes [...] Tem uma distribuição desarticulada e desequilibrada dos tempos e espaços do trabalho pedagógico; e) [...] o excesso de centralização do processo de ensino no professor (VEIGA, 2004, p. 95-96).

Nesse sentido, determinados conhecimentos são supervalorizados enquanto outros são invisibilizados e, em consequência, considera-se mais o que é produzido pelas "disciplinas acadêmicas em diferentes campos científicos", desconstruindo os saberes que os acadêmicos trazem de suas vivências em sociedade. Ou seja, "o conhecimento é visto como algo estático, que se traduz em um rol de conteúdos, competências e habilidades a serem assimilados pelos alunos de forma descontextualizada. Isso tem acentuado os problemas da exclusão e da seletividade" (VEIGA, 2004, p. 87).

Justamente nesse cerne que as LEdoCs se distinguem das demais licenciaturas. Elas são ofertadas em quatro áreas de conhecimento: 1) Artes; 2) Literatura e Linguagens; 3) Ciências da Natureza e Matemática; 4) Ciências Agrárias (MOLINA; SÁ, 2012). Nesse sentido, segundo Caldart (2011, p. 111), "a questão das áreas pode ser ancorada hoje em pelo menos três visões diferentes sobre os rumos da transformação da escola".

A primeira possibilidade é a área ancorada em uma visão neoliberal de escola. Nessa visão, não se leva em conta a apropriação do conhecimento fundamentada na produção histórica e social do saber. Busca-se "[...] um referencial pragmático e instrumental de ajustes necessários na forma escolar para que ela continue a cumprir sua função social relacionada às exigências (contraditórias) de reprodução da forma de sociedade que a criou e a sustenta" (CALDART, 2011, p. 112). Essa abordagem não contempla as finalidades formativas da LEdoC.

A segunda possibilidade é a área ancorada em uma análise histórico-crítica da escola. "A busca da desfragmentação do conhecimento dá-se, nessa abordagem, pela contextualização dos conteúdos, por meio de uma didática que os relacione com dimensões da prática social" (CALDART, 2011, p. 112). Antes de falar sobre a terceira possibilidade para as áreas, queremos atentar-nos à orientação pedagógica do método histórico-crítico. Saviani (2016, p. 21) afirma que "a pedagogia histórico-crítica entende a educação como uma atividade mediadora no 
interior da prática social" e apresenta os cinco momentos do seu método articulando com o cenário específico da Educação do Campo, tendo a prática social como ponto de partida e ponto de chegada.

O primeiro passo do método histórico-crítico é a prática social, que é comum tanto ao professor quanto ao aluno, mas é vivenciada diferentemente pelos envolvidos. Isso acontece porque o professor deve ter uma visão sintética da prática social, ou seja, "ele deverá ter uma compreensão articulada das múltiplas determinações que caracterizam a sociedade atual" (SAVIANI, 2016, p. 22). Os alunos, no ponto de partida, têm uma visão sincrética da prática social, ou seja, "[...] têm uma compreensão ainda superficial marcada pelas vivências empíricas presas às impressões imediatas" (SAVIANI, 2016, p. 22). Para o autor, na perspectiva da Educação do Campo, o professor precisa compreender a essencialidade da terra para a vida humana, bem como o problema agrário e a luta de classes no Campo, levando em conta as características específicas de cada situação.

O segundo passo desse método é a problematização, ou seja, "[...] o ato de detectar as questões que precisam ser resolvidas no âmbito da prática social e como a educação poderá encaminhar as devidas soluções” (SAVIANI, 2016, p. 36). O terceiro passo é a instrumentalização, "entendida como a apropriação dos instrumentos teóricos e práticos necessários ao equacionamento dos problemas detectados na prática social" (SAVIANI, 2016, p. 36). O quarto passo é catarse, que é "o ponto culminante do processo pedagógico, quando ocorre a efetiva incorporação dos instrumentos culturais, transformados em elementos de transformação social" (SAVIANI, 2016, p. 36). Por fim, o quinto passo (o ponto de chegada) do método proposto pela pedagogia histórico-crítica é a própria prática social, a qual passa a ser entendida em nível sintético pelos alunos.

Em suma, na visão histórico-crítica, a educação

[...] só poderá cumprir o seu papel, se os professores previamente compreenderem a historicidade do mundo atual, capacitando-se a identificar os componentes educativos nele albergados. A partir desse requisito estarão qualificados a trabalhar com os educandos os problemas postos pela prática social, propiciando-lhes o acesso aos instrumentos por meio dos quais atingirão o momento catártico em que os diferentes aspectos que compõem a estrutura social serão progressivamente elaborados na forma de superestrutura em sua 
inconsciência e incorporados como uma espécie de segunda natureza que conferirá uma nova qualidade à sua prática social"

(SAVIANI, 2016, p. 23).

Vale ressaltar que, segundo Saviani (2016, p. 37), não existe uma ordem, uma sequência, pré-determinada para realizar esse método: primeiro, a problematização, depois a instrumentação e catarse. É preciso considerar o movimento dialético da sua teoria, entendendo que "na verdade, esses momentos se imbricam". Outro aspecto importante a se destacar é sobre a prática social. Durante o processo de mediação do trabalho pedagógico, a compreensão e a vivência da prática social alteram-se qualitativamente. Assim, a prática social do ponto de partida (primeiro momento) é, e não é, a mesma do ponto de chegada (quinto momento). $O$ autor explica que

É a mesma porque é ela própria que constitui ao mesmo tempo o suporte e o contexto, o pressuposto e o alvo, o fundamento e a finalidade da prática pedagógica. $E$ não é a mesma, se considerarmos que o modo de nos situarmos em seu interior se alterou qualitativamente pela mediação da ação pedagógica

(SAVIANI, 2016, p. 38)

Logo, a orientação teórico-metodológica da pedagogia histórico-crítica trata-se de uma sequência dialética com a finalidade de compreender a existência humana em sua totalidade, tornando-se um processo consistente, coerente e eficaz na luta pela transformação da sociedade.

É importante entendermos um pouco sobre essa orientação pedagógica, porque a terceira possibilidade de ancoragem do trabalho docente por áreas, a qual deve ser assumida pela LEdoC, é a incorporação de reflexões da visão histórico-crítica da educação, "[...] em especial sobre o trabalho com os conteúdos na perspectiva da apropriação do conhecimento pela classe trabalhadora" (CALDART, 2011, p. 112), com um entendimento diferenciado sobre a abrangência da tarefa educativa da escola. Uma vez que, entende-se que "a forma da escola educa, e não apenas seus conteúdos de ensino. Por isso, é essa forma, ou seja, a lógica do trabalho escolar como um todo, que precisa ser alterada para colocá-la na direção da sociedade dos trabalhadores (isso inclui os conteúdos, mas não se restringe a eles)" (CALDART, 2011, p. 113). 
Assim, o ideal para o trabalho docente por áreas de conhecimento na LEdoC, é considerar a orientação teórico-metodológica da pedagogia histórico-crítica em função da transformação da escola integrando a junção teoria-prática, "[...] fundamentalmente práticas de trabalho e de organização coletiva dos estudantes, totalidade inserida na luta pela criação de novas relações sociais e na formação omnilateral dos trabalhadores que lhe corresponde" (CALDART, 2011, p. 114).

Cláudio Félix dos Santos, em sua obra "O 'aprender a aprender' na formação de professores do Campo" (2013), analisa criticamente os fundamentos pedagógicos da LEdoC na tentativa de refletir sobre as pedagogias contra-hegemônicas rumo à superação das relações de dominação e subordinação da classe dominada. Ele argumenta que essa modalidade de formação

[...] entra em contradição com seu enraizamento das lutas da classe trabalhadora ao adotar fundamentos teóricos oriundos do escolanovismo e do relativismo epistemológico e cultural, que se constituíram em suportes para as reformas no âmbito da formação de professores levadas a cabo, desde os anos de 1990, pelas políticas conhecidas como neoliberais" (SANTOS, 2013, p. 5).

Ainda, complementa sua ideia afirmando que, os que dedicam à construção dessa licenciatura devem ter em questão a necessidade de uma "análise crítica de projetos que se propõem a contribuir para a transformação social, mas que em suas formulações pedagógicas acabam incorporando, sem uma perspectiva de superação, as concepções hegemônicas/reacionárias no campo educacional" (SANTOS, 2013, p. 5-6). Para ele, existem muitas controvérsias acerca de algumas reivindicações dos Movimentos Sociais com relação ao papel transformador da escola. Em linhas gerais, ele enfatiza que

Alguns entendem que a escola não contribui na luta revolucionária por ser reprodutora das relações sociais dominantes. Outros avaliam que a centralidade das atividades educativas se encontra nos saberes locais e intersubjetivos existentes num mundo diverso e complexo, modulado pelas incontáveis realidades étnicas, campesinas e urbanas, cujas racionalidades e culturas são variadas. Existem aqueles que advogam uma pedagogia prática, considerando os Movimentos Sociais os portadores da nova e verdadeira educação. A forma de escola e a defesa da apropriação do conhecimento sistematizado seriam nocivas para as organizações populares. Há, ainda, os que julgam ser necessária a superação da escola atual, pois a mesma não traz a vida dos estudantes para o 
seu interior, não se preocupa com o entorno e centra sua atividade educativa no cognitivo (SANTOS, 2013, p. 90).

Todos esses argumentos acabam por desvalorizar a importância da educação escolar, enfatizando um caráter negativo ao ato educativo, uma vez que o considera prejudicial para o aluno, porque impede que ele aprenda de acordo com seus próprios interesses e curiosidade. Saviani $(2011$, p. 71$)$ afirma que no processo pedagógico os interesses dos alunos devem ser considerados, porém

O problema é o seguinte: quais são os interesses do aluno? De que aluno estamos falando, do aluno empírico ou do aluno concreto? $\mathrm{O}$ aluno empírico, o indivíduo imediatamente observável, tem determinadas sensações, desejos e aspirações que correspondem à sua condição empírica imediata. Estes desejos e aspirações não correspondem necessariamente aos interesses reais, definidos pelas condições sociais que situam enquanto indivíduo concreto. [...] Nem sempre o que a criança manifesta à primeira vista como sendo de seu interesse é de seu interesse como ser concreto, inserido em determinadas relações sociais. Em contrapartida, conteúdos que ela tende a rejeitar são, no entanto, de seu maior interesse enquanto indivíduos concretos.

Na citação acima, Saviani (2011) nos chama a atenção para o objeto específico do trabalho escolar, o saber sistematizado. Se o conhecimento científico está sendo secundarizado, diluído ou até mesmo negado diante de tantas atividades que a escola se propõe a fazer, a escola não está cumprindo seu papel. Com relação a isso, muitas vezes usa-se a expressão: Tudo o que a escola faz é Currículo! "Exemplo disso são as comemorações nas escolas, que se espalhavam por todo o ano letivo, às quais agora se associam, ou a elas são acrescidos, os denominados temas transversais, como educação ambiental, educação sexual, educação para trânsito etc." (SAVIANI, 2011, p. 87). Porém, o autor é bastante enfático ao definir Currículo como "as atividades essenciais que a escola não pode deixar de desenvolver, sob pena de se descaracterizar, de perder a sua especificidade" (SAVIANI, 2011, p. 87).

Nesse sentido, Santos (2013, p. 127) afirma: "No contexto de desvalorização da objetividade do conhecimento, nada mais coerente do que esvaziar a escola de sua função social de socializar o conhecimento objetivo. Em seu lugar, hipervalorizam-se as relações interpessoais, a experiência vivencial singular e imediata". Tanto Saviani $(1999,2011)$ quanto Santos (2013) defendem a importância 
da apropriação/assimilação de conteúdos na luta pela superação das relações sociais de exploração.

Uma possibilidade de superação da formação fragmentada de professores na perspectiva da pedagogia histórico-crítica, segundo Santos (2013, p. 131-132) citando Saviani (1932), é a formação para a licenciatura ser diferente do bacharelado, considerando que "ensino é diferente de pesquisa ou atuação no ramo profissional liberal" e a "necessidade tanto do conhecimento específico pedagógico quanto dos conhecimentos específicos das ciências que são trabalhadas na formação dos indivíduos na educação escolar" (SANTOS, 2013, p. 132). Assim, o autor finaliza que

Para a pedagogia histórico-crítica, em vez de formar os especialistas ou os generalistas por área de conhecimento, seria realmente necessário formar educadores com uma sólida fundamentação teórica, desenvolvida a partir e em função das exigências da ação educativa nas condições brasileiras, capaz de enfrentar os desafios educacionais na cidade ou no Campo, os quais não são apenas de ordem pedagógica, mas também socio-históricas e organizativas da escola e das lutas de classe (SANTOS, 2013, p. 133).

Dessa forma, levando em conta a socialização do conhecimento sistematizado, o processo escolar é entendido como o elemento de maior interesse e importância rumo à compreensão da realidade humana, construída pelos homens, a partir do processo de trabalho ao longo do tempo. Partindo da premissa marxista de que é do mais desenvolvido que se compreende o menos desenvolvido, Saviani (2011, p. 88) garante a impossibilidade de compreensão da educação sem a escola, "porque a escola é a forma dominante e principal de educação. Assim, para compreenderem-se as diferentes modalidades de educação, exige-se a compreensão da escola. Em contrapartida, a escola pode ser compreendida independentemente das demais modalidades de educação”.

Em face ao apresentado sobre a importância da superação da fragmentação do conhecimento, vamos às análises dos PPP. Teoricamente, todos os cursos atendem a esse princípio, porque oferecem a Licenciatura em Educação do Campo com habilitação em Ciências da Natureza. Porém, não é possível determinar aqui se estes estão favorecendo uma formação por áreas conforme definida por Caldart (2011) e discutida nesse Tópico. 
O P-1 (2014, p. 13, grifo nosso) possui em seus objetivos específicos o seguinte aspecto: "Formar professores para os anos finais, segundo segmento, do Ensino Fundamental e Ensino Médio, para o exercício da docência multidisciplinar em escolas do Campo nas habilitações de Ciências da Natureza e Ciências Humanas e Sociais" e também é evidenciado na página 22 do documento. Como competência e habilidade, o/a egresso deverá ter "Compreensão da lógica e do papel do trabalho interdisciplinar e transdisciplinar na produção do conhecimento pedagógico, notadamente voltado para a realidade do Campo" (P-1, 2014, p. 23, grifos nossos).

Destacamos que P-2 dispõe do mesmo objetivo específico citado em P-1, mas o curso visa também: "Preparar os/as licenciados/as em Educação do Campo para uma atuação pedagógica de perspectiva transdisciplinar e articuladoras das diferentes dimensões da formação humana” (P-2, 2013, p. 19, grifos nossos). E como competência e habilidade o mesmo mencionado pelo P-1, mas com o trabalho interdisciplinar e transdisciplinar exclusivo para a realidade local, "voltado para a realidade do Campo semiárido" (P-2, 2013, p. 26, grifos nossos). O que evidencia uma certa preocupação dos elaboradores do PPP em preparar o profissional para compreender a sua realidade, capacitando-o/a para intervir na sua localidade e transformá-la. Assim, é um aspecto importante para superar a fragmentação do conhecimento como já discutimos.

Em P-3, a formação por área nem a forma que é realizado o trabalho educativo não estão descritos especificamente nos objetivos e no perfil do egresso desejado, mas indica que o curso forma licenciados/as em Ciências da Natureza e Ciências Humanas. Lembrando que o nosso foco é na área Ciências da Natureza, porém nessa instituição é oferecida também a habilitação em Ciências Humanas.

Já P-4 (2014, p. 87, grifos nossos) sinaliza que "o licenciado em Educação do Campo é um profissional da educação habilitado para o trabalho educativo multidisciplinar em áreas de conhecimento das Ciências da Natureza (Biologia, Física e Química) ou Matemática". E P-5 (2013, p. 38, grifos nossos) evidencia nos seus objetivos específicos, que o curso deverá "explorar e promover práticas interdisciplinares na trajetória do curso, ressaltando-se que a vivência de experiências desta natureza na formação inicial dos licenciandos possa referenciar o 
acadêmico em relação ao exercício da docência". Além, no "Perfil do Egresso" é apresentado que

Pretende-se, também, que os futuros professores tenham além de uma formação sólida, que aprendam como se trabalha e se pesquisa em Ciências, Biologia, Física e Química, quais procedimentos, experiências e cálculos, enfatizando conteúdos atuais que podem ser utilizados como instrumentos para a compreensão do mundo contemporâneo (P-5, 2013, p. 39, grifos nossos).

Logo, se espera que o professor recém-formado trabalhe e pesquisa na área de Ciências da Natureza de forma multi, trans e interdisciplinar. Ressaltamos que em alguns PPPs esses termos parecem-nos ser empregados com um sentido único de interdisciplinaridade. Mas, suas definições são distintas. Segundo Pires (1998, p. 176, grifos da autora):

A multidisciplinaridade parece esgotar-se nas tentativas de trabalho conjunto, pelos professores, entre disciplinas em que cada uma trata de temas comuns sob sua própria ótica, articulando, algumas vezes bibliografia, técnicas de ensino e procedimentos de avaliação. Poder-se-ia dizer que na multidisciplinaridade as pessoas, no caos as disciplinas do Currículo escolar, estudar perto mas não juntas.

Sobre o trabalho interdisciplinar e transdisciplinar, salientamos que é uma forma de organização do Currículo. Entretanto, destacamos que para haver uma interdisciplinaridade efetiva é necessário "[...] estruturar o Currículo de forma a proporcionar uma visão ampla e atual da ciência numa organização aberta que permita estabelecer relações interdisciplinares e articulações conceituais não só no campo de saberes de referência como em outros campos" (VEIGA, 2004, p. 105).

Assim, entendemos que "a interdisciplinaridadeestimula o diálogo entre conhecimentos e, ao mesmo tempo, sua fragmentação em generalidades. Significa, portanto, o estabelecimento de conexões entre diferentes saberes e diferentes áreas de conhecimento. A interdisciplinaridade é coletiva" (VEIGA, 2004, p. 66).

Ressaltamos que a diferença entre interdisciplinaridade e transdisciplinaridade efetiva-se na medida em que a primeira está relacionada à melhor compreensão do significado de conceitos, das razões e métodos a partir da realidade, enquanto a segunda, na superação das fronteiras entre as disciplinas. Caldart (2011, p. 109) nos esclarece que: 
[...] a interdisciplinaridade, como método, "é a reconstituição da totalidade pela relação entre os conteúdos originados a partir de distintos recortes da realidade; isto é, dos diversos campos da ciência representados em disciplinas. Isso tem como objetivo possibilitar a compreensão do significado dos conceitos, das razões e dos métodos pelos quais se pode conhecer o real e apropriá-lo em seu potencial para o ser humano" (RAMOS, 2005, p. 116). A transdisciplinaridade pode ser entendida como um esforço de efetiva superação das fronteiras entre as disciplinas, compondo "novos arranjos de conteúdos das várias áreas do conhecimento, articulados por eixos temáticos definidos pela práxis social", ainda que sem desconsiderar no tratamento desses conteúdos os saberes disciplinares, mas podendo ir além deles (KUENZER, 2003).

Os cinco PPPs analisados defendem a importância da interdisciplinaridade ser explorada no curso, em razão de oferecer práticas interdisciplinares para os recém-formados/as fundamentarem o exercício de suas próprias docências. Visto que, "perceber-se interdisciplinar é sobretudo acreditar que o outro também pode ser ou tornar-se interdisciplinar" (FAZENDA, 2012, p. 78, grifos da autora).

Citando os documentos, P-1 (2014, p. 14) sustenta sua fundamentação filosófica (materialismo histórico e dialético) apontando a questão da interdisciplinaridade como uma orientação relacionada à Pedagogia da Alternância, pressupondo o reconhecimento de saberes multifacetados, bem como a possibilidade de ver o mundo a partir de uma realidade globalizante "pela associação dialética entre dimensões polares, como por exemplo, teoria e prática, ação e reflexão, generalização e especialização, ensino e avaliação, meios e fins, conteúdos e processos, indivíduo e sociedade etc.". P-2 (2013, p. 34) se posiciona como um curso interdisciplinar ao esclarecer a lógica da organização curricular, destaca que

o conjunto das áreas temáticas se articula nos diferentes núcleos e atividades, de modo a garantir uma formação interdisciplinar a partir de uma organização curricular disciplinar por áreas do conhecimento, tal qual o preconizado no Projeto Pedagógico Institucional - PPI da UFERSA.

P-3 (2017, p. 81) apresenta a definição de interdisciplinaridade, pautando que todos os professores do curso devem desenvolver um trabalho coletivo e interdisciplinar, desde o planejamento das atividades, acompanhamento/desenvolvimento e avaliação: 
a interdisciplinaridade na formação profissional requer competências relativas às formas de intervenção solicitadas e às condições que concorrerem ao seu melhor exercício. Neste caso, os desenvolvimentos das competências necessárias requerem a conjugação de diferentes saberes disciplinares. Entenda-se por saberes disciplinares: saberes da experiência, saberes técnicos e saberes teóricos interagindo dinamicamente sem nenhuma linearidade ou hierarquização que subjugue os profissionais participantes.

Ainda argumenta que a UFGD, ao apresentar seus aspectos históricos de experiências com pessoas do Campo, pretende

envolver aspectos da vida cotidiana e da construção de sujeitos sociais no Campo, cujo conhecimento se pretende aprofundar, de modo sistemático, num trabalho coletivo interdisciplinar, englobando os complexos aspectos dos processos de desenvolvimento sócio rural, da produção ecológica, das relações de gêneros, de gerações e etnias distintas que convivem no Campo (P-3, 2017, p. 13).

P-4 (2014, p. 65) também apresenta que o curso tem uma dinâmica essencialmente interdisciplinar, destacando que "o trabalho interdisciplinar a partir dos componentes curriculares constituirá um espaço para a formação de grupos de estudos e pesquisas, a fim de criar um ambiente de fomento às iniciativas, aos estudos e às atividades científicas em diferentes áreas do conhecimento". E justifica que a interdisciplinaridade "reside no conhecimento da realidade em uma perspectiva relacional" (p. 66). Por fim, P-5 (2013, p. 45) enfatiza que um dos principais desafios do curso é a prática interdisciplinar, uma vez que

a realização da interligação entre componentes curriculares de diferentes áreas de conhecimento tem como princípio didático a interdisciplinaridade, em que se procura interpretar a realidade tendo em vista a multiplicidade de leituras, de modelos de construir conhecimento, para o que é necessário observar os fatos e fenômenos sob múltiplos olhares.

Considerando esse aspecto o documento define o termo a partir de Morin, entendendo que

a interdisciplinaridade consiste em troca, cooperação, pois o conhecimento é um movimento articulado entre saberes, ou seja, é relacional. Dessa maneira, para que a prática interdisciplinar ocorra no curso precisa ser integrado, promovendo trocas entre os diversos campos do saber que envolve a formação do professor (P-5, 2013, p. 46). 
Então, podemos considerar que "executar uma tarefa interdisciplinar pressupõe antes de qualquer coisa um ato de perceber-se interdisciplinar" (FAZENDA, 2012, p. 77, grifos da autora, concordando com os PPPs ao abordarem essa perspectiva interdisciplinar nos cursos com a finalidade de construir profissionais compromissados/as com o agir colaborativo, participativo e corresponsável.

Ainda, como superação dos modelos hegemônicos têm-se a necessidade de refletir sobre práticas pedagógicas que superem padrões abissais de ensino e que valorizem e reconheçam outras formas de conhecimentos e saberes, além do conhecimento científico.

\section{Considerações Finais}

Os PPPs analisados concebem a formação crítica/conscientizadora/reflexiva capaz de transformar a realidade local, regional e nacional a partir da compreensão do contexto social, político, econômico, cultural e educacional.

Entendemos que a atual formação de professores prevê uma formação genérica, à medida que acredita que todo professor está capacitado para desenvolver seu papel independentemente das subjetividades/heterogeneidades de seu alunado. Todavia, sem a superação da formação genérica de professores não há mudança, não há como transformar a escola. Uma vez que é pela formação específica, contra-hegemônica, crítica/problematizadora, que conseguiremos construir, instruir, professores/educadores compromissados com a transformação política e social e com a formulação de práticas escolares e educativas capazes de cumprir os objetivos desse processo formativo e as intencionalidades da Educação do Campo.

Os cinco PPPs analisados demonstram interesse em superar esse protótipo de formação docente, trazendo como de suma importância a especificidade da formação docente para a atuação do professor no Campo. Apenas o documento P-5 aborda esse princípio de modo contraditório, pois explicitam primar por uma formação generalista e específica ao mesmo tempo. 
A formação por áreas de conhecimento visa superar a fragmentação tradicional que dá centralidade à forma disciplinar e mudar o modo de produção do conhecimento na Universidade e na escola do Campo, tendo em vista a compreensão da totalidade e da complexidade dos processos encontrados na realidade, justamente nesse cerne que as LEdoCs se distinguem das demais licenciaturas, elas são ofertadas em quatro áreas de conhecimento: 1) Artes; 2) Literatura e Linguagens; 3) Ciências da Natureza e Matemática; 4) Ciências Agrárias.

Em face da superação da fragmentação do conhecimento, teoricamente, todos os cursos atendem a esse princípio, porque oferecem a Licenciatura em Educação do Campo por área do conhecimento. Porém, não é possível determinar aqui se estes estão favorecendo alguma área de formação, ou dentro da própria área estar favorecendo alguma área do saber em detrimento de outra. Contudo segundo os PPPs se espera que o professor recém-formado trabalhe e pesquisa na área Ciências da Natureza de forma multi, trans e interdisciplinar. Ressaltamos que em alguns PPPs esses termos pareceram-nos ser empregados com um sentido único de interdisciplinaridade. Mas, suas definições são distintas.

Devemos considerar que essa licenciatura não possui diretrizes curriculares para a formação de professores, logo há muito a ser feito e refeito, contudo não podemos esmaecer do sentimento que para a superação dos modelos hegemônicos têm a necessidade de refletir sobre práticas pedagógicas que superem padrões abissais de ensino e que valorizem e reconheçam outras formas de conhecimentos e saberes, além do conhecimento científico.

\section{Referências}

ARROYO, Miguel G. Formação de educadores do Campo. In: CALDART, Roseli Salete; PEREIRA, Isabel Brasil; ALENTEJANO, Paulo; FRIGOTTO, Gaudêncio (Orgs.). Dicionário da Educação do Campo. - 2. ed. Rio de Janeiro, São Paulo: Escola Politécnica de Saúde Joaquim Venâncio, Expressão Popular, 2012, p. 359-365.

BASSO, Jaqueline Daniela. SANTOS NETO, José Leite dos. BEZERRA, Maria Cristina dos Santos (Orgs.). Pedagogia histórico-crítica e educação do Campo: história, desafios e perspectivas atuais. São Carlos, SP: Pedro e João Editores e Navegando, 2016, p. 16-43. 
BRASIL. Diretrizes Curriculares Nacionais Gerais da Educação Básica. Ministério da Educação. Secretaria de Educação Básica. Diretoria de Currículos e Educação Integral. - Brasília: MEC, SEB, DICEI, 2013.

BRANDÃO, Carlos Rodrigues. O que é educação popular. São Paulo: Brasiliense, 2012.

CALDART, Roseli Salete. Licenciatura em Educação do Campo e projeto formativo: qual o lugar da docência por área. In: MOLINA, Mônica Castagna. SÁ, Laís Mourão (Orgs.). Licenciaturas em Educação do Campo - Registros e reflexões a partir das experiências-piloto (UFMG; UnB; UFBA e UFS), Belo Horizonte: Autêntica Editora, 2011, p. 95-121.

FARIAS, Magno Nunes. FALEIRO, Wender. Princípios do movimento de Educação do Campo: análise dos Projetos Político-Pedagógicos das LEdoCs do Centro-Oeste brasileiro. Uberlândia, MG: Navegando Publicações, 2019.

FAZENDA, Ivani C. Arantes. Interdisciplinaridade: história, teoria e pesquisa. 18. ed. Campinas, SP: Papirus, 2012.

FREIRE, Paulo. Pedagogia da autonomia: saberes necessários à prática educativa. - 56. ed. Rio de Janeiro/São Paulo: Paz e Terra, 2018.

FREIRE, Paulo. Pedagogia do Oprimido, 64. ed. Rio de Janeiro: Paz e Terra, 2017.

FREIRE, Paulo. Política e educação: ensaios. 5. ed. São Paulo: Cortez, 2001.

KRONBAUER, Luiz Gilberto. Ação-reflexão. In: STRECK, Danilo R.; REDIN, Euclides; ZITKOSKI, Jaime José (Orgs.). Dicionário Paulo Freire. - 3. ed. 1. reimp. Belo Horizonte: Autêntica Editora, 2017, p. 23, 24.

MOLINA, Mônica Castagna. SÁ, Laís Mourão. Licenciatura em Educação do Campo. In: CALDART, Roseli Salete. PEREIRA, Isabel Brasil. ALENTEJANO, Paulo.

FRIGOTTO, Gaudêncio. (Orgs.) Dicionário da Educação do Campo, 2. ed. Rio de Janeiro, São Paulo: Escola Politécnica de Saúde Venâncio, Expressão Popular, 2012, p. 468-474.

MOREIRA, Carlos Eduardo. Criticidade. In: STRECK, Danilo R.; REDIN, Euclides; ZITKOSKI, Jaime José (Orgs.). Dicionário Paulo Freire. - 3. ed. 1. reimp. Belo Horizonte: Autêntica Editora, 2017, p. 97, 98.

PERES, Maria Regina; SANTANA, Andréia da Cunha Malheiros. Formação inicial e continuada de professores: entre avanços e tropeços. In: SANTOS, Flávio Reis dos; ROTHEN, José Carlos (Orgs.). Políticas públicas para a educação no Brasil: entre avanços e retrocessos. - São Carlos: Pixel, 2016, p. 127-142.

PIRES, Marília Freitas de Campos. Multidisciplinaridade, interdisciplinaridade e transdisciplinaridade no ensino. In: Interface - Comunicação, Saúde, Educação, v. 
2, n. 2, fev. 1998, p. 173-182. Disponível em: http://www.scielo.br/pdf/icse/v2n2/10.pdf, acesso em 21/11/2019.

SANTOS, Cláudio Félix dos. O "aprender a aprender" na formação de professores do Campo. Campinas, SP: Autores Associados; Vitória da Conquista, BA: Edições UESB, 2013.

SAVIANI, Dermeval. A pedagogia histórico-crítica na Educação do Campo. In:

SAVIANI, Dermeval. Escola e democracia: teorias da educação, curvatura da vara, onze teses sobre educação e política, 32. ed. Campinas, SP: Autores Associados, 1999.

SAVIANI, Dermeval. Pedagogia histórico-crítica: primeiras aproximações, 11. ed. rev. Campinas, SP: Autores Associados, 2011.

SOARES, Magda. Linguagem e escola: uma perspectiva social. 18. ed. São Paulo: Contexto, 2017.

VEIGA, IIma Passos Alencastro. Educação Superior: Projeto Político-Pedagógico. Campinas, SP: Papirus, 2004. (Coleção Magistério: Formação e Trabalho Pedagógico).

VEIGA, Ilma Passos Alencastro. Projeto Político-Pedagógico da Escola: uma construção possível. 29. ed. Campinas, SP: Papirus, 2013

\section{Geize Kelle Nunes Ribeiro}

Mestra em Educação pela Universidade Federal de Catalão - UFCat. Pesquisadora do do Grupo de Estudos, Pesquisa e Extensão em Ensino de Ciências e Formação de Professores - GEPEEC - UFCat/CNPq. Correio eletrônico geize.ribeiro1@gmail.com.

\section{Wender Faleiro}

Pós Doutor em Educação pela PUC-GO. Professor da Faculdade de Educação e do Programa de Pós-Graduação em Educação da Universidade Federal de Catalão - UFCat. Líder Grupo de Pesquisa e Extensão em Ensino de Ciências e Formação de Professores GEPEEC UFCat/CNPq. Correio eletrônico wender.faleiro@gmail.com. 